\title{
Parent Personality Traits During Covid-19 Pandemic: a Correlational Study
}

Cristina S. Sălăgean, Editha Coşarbă 


\title{
Parent Personality Traits During Covid-19 Pandemic: a Correlational Study
}

\author{
Cristina S. Sălăgean ${ }^{a^{*}}$, Editha Coşarbă ${ }^{b}$ \\ ${ }^{a, b}$ Doctoral School "Education, Reflection, Development”, Babes-Bolyai University Cluj-Napoca, 7 Sindicatelor Street, 400029, Romania \\ *Corresponding author: salcristina@yahoo.com
}

\section{Abstract}

Keywords:

Covid-19; parents; anxiety; selfefficacy; distrust.
The COVID-19 pandemic has had a sudden and profound impact on international communities. The emergence of COVID-19 has led to drastic measures to ensure social distancing throughout the world, in order to prevent disease. In Romania, prevention measures regarding the infection with the new coronavirus and the limitations imposed at national level suddenly changed the routines and interactions of the population and made many parents feel overwhelmed due to work at home, home-schooling and family care, simultaneously. The national home quarantine policy may have influenced parents' mental health. The present study aimed to investigate the anxiety, self-efficacy, anger, energy level, distrust and frustration about the basic psychological needs of parents during the COVID-19 pandemic and to explore the relationship between them.

\section{Zusammenfasung}

Schlüsselworte:

Covid-19; Eltern; Angst;

Selbstwirksamkeit; Misstrauen.
Die COVID-19-Pandemie hatte plötzliche und tiefgreifende Auswirkungen auf die internationalen Gemeinschaften. Das Aufkommen von COVID-19 hat zu drastischen Maßnahmen geführt, um die soziale Distanzierung auf der ganzen Welt sicherzustellen und Krankheiten vorzubeugen. In Rumänien veränderten Präventionsmaßnahmen in Bezug auf die Infektion mit dem neuen Coronavirus und die auf nationaler Ebene auferlegten Einschränkungen plötzlich die Routinen und Interaktionen der Bevölkerung und ließen viele Eltern sich aufgrund der Arbeit zu Hause, der Schule zu Hause und der familiären Betreuung zu Hause gleichzeitig überfordert fühlen. Die nationale Hausquarantänepolitik hat möglicherweise die psychische Gesundheit der Eltern beeinflusst. Die vorliegende Studie zielte darauf ab, die Angst, Selbstwirksamkeit, Wut, Energie, Misstrauen und Frustration über die psychologischen Grundbedürfnisse der Eltern während der COVID-19. Pandemie zu untersuchen und die Beziehung zwischen ihnen zu untersuchen.

\section{Introduction}

On December 31, 2019, in the Hubei region of China, several cases of pneumonia of unknown etiology were found, and a week later, the causative factor was identified as a virus belonging to the Coronaviridae family called SARS-CoV-2 (severe acute respiratory syndrome coronavirus 2 ). This new coronavirus was responsible for the respiratory syndrome called COVID-19 (World Health Organization [WHO], 2020). The disease began to spread in China, with a huge rate of contagion and deaths, which led the World Health Organization (WHO) to declare, on January 30, 2020, a public health emergency of international interest. A few weeks later, the disease was detected in many countries, COVID-19 being declared a WHO pandemic on March 11, 2020.

Although most patients who came in contact with the virus developed only mild symptoms, such as fever, dry cough, and lack of odor, with a benign course and easy recovery, some patients developed severe complications, such as pulmonary edema, interstitial pneumoniae with acute respiratory distress syndrome, multiorgan failure, septic shock, and even death (Sohrabi et al., 2020). Patients at risk were those over 60 years of age, suffering from cardiovascular comorbidities (e.g., arterial hypertension, diabetes, and chronic coronary artery disease) and affected by chronic pneumopathies or cancer (Zhou et al., 2020). In the spring of 2020, governments around the world were forced to impose drastic measures of social distancing to reduce the spread of the virus. The pandemic has caused an economic and social burden that is difficult to estimate.

This virus has become a threat not only to people's physical health, but also to their mental health. A survey conducted in China showed that almost $35 \%$ of the population suffered significant psychological distress and a variety of psychological problems, for example, anxiety (Qiu et al., 2020). Evidence of emotional impairment was also found in Western 
countries during the acute period of the pandemic (Mazza et al., 2020). Therefore, the study of mental health during the pandemic is one of the most important challenges for research, policy makers and administrations (Romero et al., 2020).

Most studies conducted so far, since the beginning of the COVID-19 outbreak or during previous pandemics have examined the psychological consequences on the general population, the analysis of effects on parents being neglected, with few exceptions. A deeper understanding of risk factors in the home environment, such as parents' mental health issues, is, therefore, very important (Spinelli et al., 2020; D. Wang et al., 2020).

This study examines the relationships between some parental personality traits, during Covid-19 pandemic.

\section{Theoretical foundation}

Considering the Covid-19 pandemic, the President of Romania decreed a state of emergency on the territory of Romania on March 16, 2020, for 30 days, and later, on April 14, it was extended for another 30 days. The establishment of a state of emergency in Romania came just several days after the World Health Organization declared a coronavirus pandemic. The state of emergency decreed in March included first-rate measures with direct applicability in the areas of public order, economics, health, labor and social protection, justice and foreign affairs, as well as firstrate measures with gradual applicability (Digi24, 2020).

When this study was conducted, schools and child care institutions in Romania were closed, over 1 million employment contracts were suspended, and the unemployment rate reached almost 7\% (Digi24, 2020). During the most restrictive period, the state of emergency, which lasted 2 months, families had to suddenly adapt their routines, work and interactions, coping with various sources of stress related to health, family health and work.

The policy of transferring learning activities from school to home had implications for changing the learning model. Some schools and teachers used several online facilities and platforms to continue teaching, but the care for children to understand the materials received, to participate in online classes and to do their homeworks was transferred to the parents. The transition from school to home-based learning has taken parents by surprise. This ideal of online schooling did not follow, in reality, the facts on the ground. Online learning has caused a lot of disorientation (Sari et al., 2020). The teacher expected home learning to be done with online assignments, and the assessment was online. They often gave tasks that required several hours to complete. As a result, tasks accumulated, and children and parents were exhausted (Sari et al., 2020).

In addition to school activities, parents were put in the situation of continuously looking for indoor leisure activities and managing children's behavior problems throughout the day. A great challenge of learning at home through the use of online learning was felt more accentuated by families with minimum economic incomes (Tedeschi et al., 2018).

Research suggests that parents experience stronger and negative responses to more acute disasters, increased anxiety and post-traumatic stress compared to those with fewer caring responsibilities (Bradley, 2007; Conger et al., 2002; Gewirtz et al., 2008; Xie et al., 2020). Parents are put in a situation where they have to find resources, in terms of their own coping and self-care, as well as their children who take the model of parents to cope with stressful situations (Deater-Deckard, 1998).

Families with children have faced many difficulties due to the loss of economic and social support. In America, more than 1 in 4 parents reported mental health problems and 1 in 7 parents reported worsening of their children's behavioral problems since the pandemic began (Patrick et al., 2020). A study in China reported that children face fear, clinging, inattention, and irritability during the COVID-19 pandemic (Jiao et al., 2020).

In general, in good times, when there is no pandemic, many parents experience specific stress related to their parenting roles (Kaya \& Fang, 1997; Mikkonen \& Raphael, 2010). For most parents, stress related to the role of parents is transient and does not result in a significant impact on life (Roskam et al., 2018; Séjourné et al., 2018). Parental unemployment, financial insecurity, low levels of social support from family and friends and lack of free time were associated with an increased risk of parental exhaustion (Lindström et al., 2011; Sorkkila \& Aunola, 2020).

Factors that influence anxiety of parents include marital satisfaction, family conflicts, social support, 
history of mental illness, parental style, level of development of the child, etc. (Wu et al., 2020).

Given the COVID-19 pandemic, parental suffering could have specific triggers, such as isolation at home, social distancing, difficulties in keeping family members safe, difficulties in keeping children busy, difficulties in supporting children's learning, difficulties in meeting the needs and requirements of children, however, while facing their own emotional issues (Romero et al., 2020). It has been suggested that parents' self-efficacy (Bandura, 1983) may protect them from life's stressors.

The results of a study by Spinelli et al. (2020) showed that the perceived difficulty of quarantine is a factor that significantly influences the well-being of both parents and children. The impact of quarantine on children's behavioral and emotional problems is mediated by the individual and dyadic stress of parents (Spinelli et al., 2020).

Just like on a plane, parents are advised to put on their own oxygen masks first, when it is an emergency, so that they can support their children effectively and keep them safe in the same way. In any crisis situation, parents must be taught how to take care of themselves if they want to support their children effectively (Coyne et al., 2020).

As parents' demands and stress increase, so do resources. Many children could become victims of domestic abuse (Usher et al., 2020). Parents face a collision of roles - employee, parent, partner, employer, business owner, friend, caregiver, teacher, etc. As they manage this collision of roles, responsibilities, and expectations, they may face fear and uncertainty about the future and how they can keep their families safe (Coyne et al., 2020). While parental suffering can cause negative outcomes for children, good mental health for parents has been more closely linked to positive outcomes for children (Romero et al., 2020).

Reports from families during the peak of COVID19 in the US indicate these stressors as being increased for parents or caregivers: anxiety or fear of infection, major changes in work / learning, daily personal care routines, and poor access to reliable information and resources (Norris et al., 2002; Prime et al., 2020; Russell et al., 2020; C. Wang et al., 2020; Xie et al., 2020).

Maintaining routines and structure in the family environment is important because routines foster a sense of coherence and management (Bradley, 2007; Romero et al., 2020). Interruption of routines, closure of schools, limitation of health care visits and changing eating habits were contributed to the deterioration of mental and behavioral health among families (Patrick et al., 2020).

Family systemic theory and parental research say that the role of parents is very complex (Connor \& Davidson, 2003; Gordillo, 2020) including the perceived responsibility to respond to the needs of multiple family subsystems. High levels of psychological distress can negatively influence the balance of care responsibilities, with parents often sacrificing their own well-being to meet the care needs of their children (Neece et al., 2012; Sameroff, 2009). Lack of adequate financial resources that leads to frustration in meeting basic needs is a factor that aggravates the mental health of the general population (Russell et al., 2020).

The COVID-19 pandemic has put many parents in a position to make difficult choices. Some have had to choose between going back to work, with the potential contamination of their homes, and working from home while coping with the growing demands for children's home education. Others had elderly parents or family members with chronic illnesses that they had to take care of and ensure their safety. For parents of children with disabilities or other health problems, the challenges were even greater.

Anxiety has been observed in parents who go to work, which can put them at high risk of contagion, but also the situation of isolation at home has led parents to face different threats (eg management workrelated problems, keeping safe, difficulties and challenges in managing the child's school work, meeting the child's needs and demands for attention, while dealing with their own emotional problems). These difficulties can create a feeling of discomfort with the requirements of care, which is combined with symptoms of anxiety in accordance with previous findings in various fields of research (Romero et al., 2020; Shea \& Coyne, 2011; Williford et al., 2007).

The study by Gassman-Pines et al. (2020) has the advantage of using daily survey data collected before and after the pandemic to investigate the hypothesis that the pandemic has worsened the psychological well-being of parents and children. The data showed that the frequency of daily negative moods reported by parents has increased significantly since the beginning of Covid-19 pandemic (Gassman-Pines et al., 2020). 
The same daily survey data show that psychological suffering has increased in response to the current pandemic in a matter of days (Gassman-Pines et al., 2020).

With the closure of the schools and the onset of the emergency due to the pandemic, many parents began to work from home. This has significantly blurred the temporal and spatial boundaries between paid work and caring for others (Craig \& Churchill, 2020). They had to deal with a new balance between working fulltime at home and home schooling. Those who continue to work outside the home are likely to work in environments that place them at a high level of personal risk, such as hospitals, clinics, grocery stores, and pharmacies.

The balancing of work and family was assisted by government policies, which applied, however, only to employed parents, who are not medical staff. Some of the parents had the right to apply for part-time work, flexible working hours and options for working from home. However, many parents do not have access to "family-friendly" workplace measures and even when they are officially available, there may be unwritten sanctions against access to them (Craig \& Churchill, 2020).

In many cases, families have suffered the negative effects of unemployment and the collapse of economic markets. Research results have also indicated that lower-income families are more significantly affected in terms of well-being during the pandemic, making them even more vulnerable to illness (Coyne et al., 2020).

In addition to high levels of unemployment and financial insecurity, access to traditional social support from extended family and friends has been limited. Many parents often relied on the support of grandparents or other family members for child care or help with household chores. However, due to the requirements of social distancing, this is no longer a possibility, as many grandparents fall into the category of "increased risk" of COVID-19-related diseases, or even death, due to their age or the presence of underlying health conditions.

Many parents also experience loss of access to common sources of socializing and leisure activities, such as churches, fitness centers, bars and restaurants, and in-person interactions with friends. All of these changes and limiting breaks away from home and away from children can put parents at greater risk of parental exhaustion. They have difficulty making time for themselves and finding a balance between their personal, professional and parental responsibilities (Parkes et al., 2015).

Research shows that mental health problems following community-wide disasters or natural crises are widespread, with an impact on individuals and families (Russell et al., 2020). It is known that exposure to a wide range of disasters has a negative impact on mental health and can lead to prolonged periods of increased psychiatric symptoms, including anxiety (Cobham et al., 2016; Gewirtz et al., 2008; McFarlane, 1987; Rodrigo et al., 2012). Factors that can have an impact on mental health include prolonged isolation, distrust, fear of infection, anger, stress, frustration, boredom, inadequate supplies and information, financial loss, and stigma (Costa et al., 2009).

Experts warn that the COVID-19 pandemic can lead to traumatic stress and can exacerbate existing mental health difficulties and lead to the development of new disorders for an extended period of time (Masten \& Osofsky, 2010).

A large survey conducted in China showed that $35 \%$ of the population suffered psychological distress during the COVID-19 outbreak. The response to stress caused by such public health events is generally manifested as anxiety (Wu et al., 2020).

\section{Research methodology}

\subsection{Participants and procedure}

Our sample was formed of 128 participants, parents of primary school pupils, from 15 counties and 32 cities in Romania. Participants $(\mathrm{N}=128)$ completed a questionnaire about demographic characteristics and data about their socio-economic living conditions and how they related to prevention measures (quarantine, school closures, work from home) during the Covid19 pandemic. The sample was selected on-line through a form that was distributed on social networks.

From the sample, $91.40 \%$ were women (mothers) and 8.59 were men (fathers). $0.78 \%$ are between 18 and 25 years old, $39.84 \%$ are between 26 and 35 years old, 52.34\% are between 36 and 45 years old and $7.03 \%$ are between 46 and 55 years old. Regarding marital status, among the participants, $91.40 \%$ are married, $0.78 \%$ live in cohabitation, $1.56 \%$ are unmarried and $6.25 \%$ are divorced. 
Regarding the graduated studies, $2.34 \%$ of the participants completed only grades V-VIII, 9.37\% completed the vocational school, $13.28 \%$ graduated only high school, $72.65 \%$ have a bachelor's or master's degree and $2.34 \%$ completed their doctoral studies.

Regarding the socio-economic situation, $14.84 \%$ of the participants have no income. Of these, $10.52 \%$ come from families in which neither the partner has any income, $15.26 \%$ are single and $15.26 \%$ have a partner who has an income below the average salary in the economy. The others have a partner who has at least an income equal to the average salary in the economy.

$11.71 \%$ of participants have an income below the average salary in the economy. Of these, $13.33 \%$ are from families where the partner has no income, $13.33 \%$ are single and $20 \%$ are from families where the partner has an income below the minimum wage in the economy. Therefore, $73.43 \%$ of the participants have incomes at least equal to the average salary per economy and $26.56 \%$ have an income below the average salary per economy or have no income.

$24.21 \%$ have only one child in care, $45.31 \%$ have 2 children, $21.85 \%$ have 3 children and $8.59 \%$ have more than 3 children.

Figure 1. Percentage of parents participating in the study depending on the number of hours they spend with their children in school activities at home

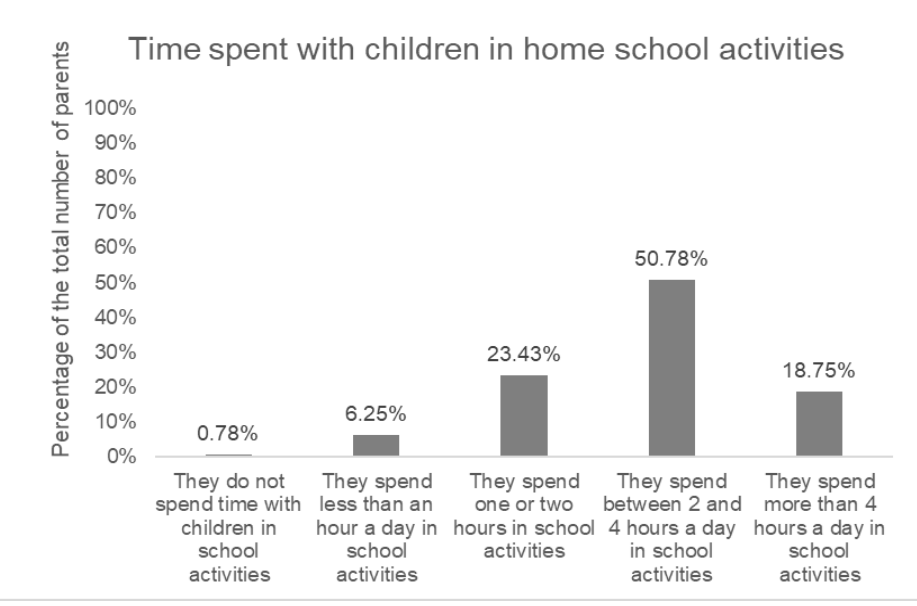

As can be seen in Figure 1, 0,78\% of the parents, participants in our study, do not spend time with their primary school children in home school activities, $6,25 \%$ of parents spend less than an hour a day in school activities with their children, $23,43 \%$ spend one or two hours in school activities, more than a half of the parents spend between 2 and 4 hours a day in school activities and $18,75 \%$ spend more than 4 hours a day in home school activities with their children. During the study, all children did all school activities at home, due to the closure of schools. $77.5 \%$ of parents manage very well to help their children in school activities. It is them easy to explain to them and consider that they understand contents.

$10.15 \%$ of the parents participating in the study suffer from medical conditions that are considered risk factors for severe forms of illness with Covid-19. $5.46 \%$ of participants suffer from an autoimmune disease, $2.34 \%$ suffer from high blood pressure, $0.78 \%$ suffer from diabetes and $1.56 \%$ suffer from other chronic diseases. $18.75 \%$ of the participants live in the same house with a person suffering from a chronic illness.

Only $2.34 \%$ of parents believe that they are very likely to have been in direct contact with a person infected with Covid-19. The other $97.65 \%$ of parents say they did not come or are very unlikely to come into direct contact with a person infected with Covid-19.

In Figure 2, the percentage of the total number of parents and their work conditions during Covid-19 pandemic were presented. $45.70 \%$ of the parents work from home, $17.18 \%$ of the parents are going to work, $17.18 \%$ of the parents are in furlough or unemployed and $18.70 \%$ of the parents are not working.

Figure 2. The percentage of the total number of parents and their work conditions during Covid-19 pandemic

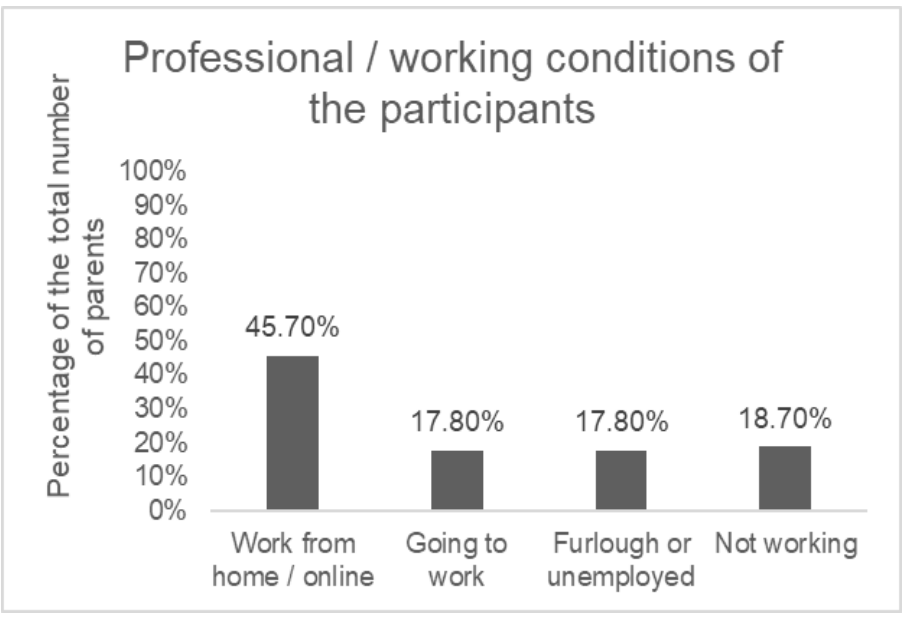

In Figure 3. we presented the extent to which the parents complied or not with the official recommendations regarding the isolation at home and the percentage of the number of parents who were in quarantine imposed by the authorities at the time of the study. 
Figure 3. The percentage of the number of parents and their compliance with isolation or quarantine recommendations

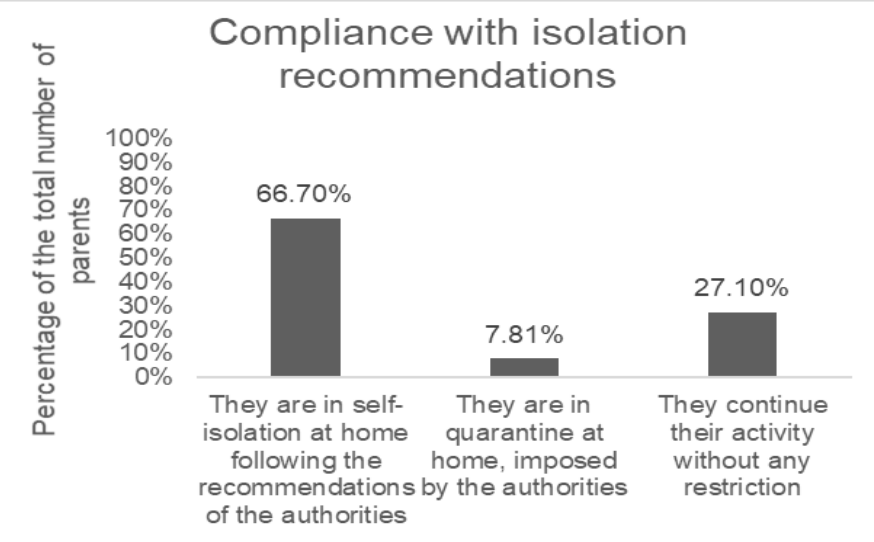

In the following figure, Figure 4, we will present to what extent the parents participating in the study comply with the self-isolation recommendations proposed by the authorities. The situations in that they were allowed to leave the house during the emergency state imposed by the state were: moving between home and work, when the professional activity it is essential and cannot be organized in the form of distance work or travel or for professional reasons that cannot be postponed; specialized medical consultation that cannot be postponed; travel for basic shopping at commercial units in the home area; travel to provide care for the elderly, vulnerable or to accompany children; short trip, close to home, for individual physical activities, excluding any form of collective sports activity; short trip, close to home, related to the needs of pets.

Figure 4 . The percentage of the number of parents and their compliance with isolation or quarantine recommendations, related to the time spent in isolation

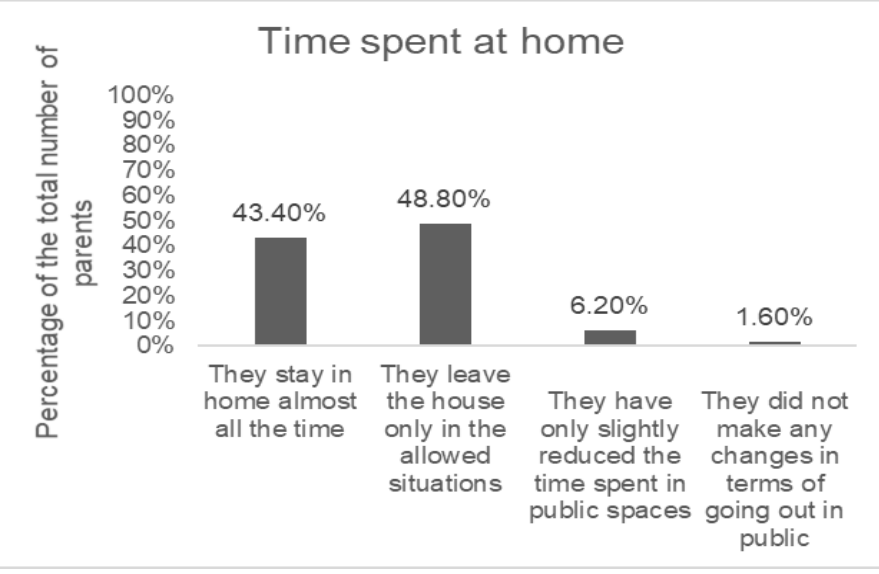

$43.40 \%$ of the parents stay home almost all the time, $48.80 \%$ of them are only leaving the home in the allowed situations described before, $6.20 \%$ have only slightly reduced the time spent in public spaces and $1.60 \%$ of them didn't make any changes. They continue the way of living they had before of the pandemic. $23.3 \%$ of parents leave home every day, $25.6 \%$ leave home 2 or 3 times a week, $30.2 \%$ of parents leave once a week and $20.9 \%$ leave the house only once in a few weeks.

We asked parents how often they seek information through the media about the local, national or international situation regarding the evolution of the Covid-19 pandemic. $74.6 \%$ of them are looking for information about the Covid-19 pandemic a few hours a day. $38 \%$ follow the news about the pandemic only once a day, $13.2 \%$ look for information every few days and $3.1 \%$ do not look for information at all.

We also investigated the perceived social support that parents benefit from. $83.7 \%$ of parents said that they can count on the help of their family members during the COVID-19 pandemic, $31 \%$ of them benefit from the help of friends in need, $17.8 \%$ benefit from the help of neighbors, $14 \%$ from that of co-workers. $10.1 \%$ of participants do not have support from family, friends, neighbors or co-workers.

\subsection{Instruments}

For measuring the anxiety and anger of the participants, we used the N1: Anxiety subscale and the N2: Anger subscale from The Neuroticism Factor (N) in The 30 NEO-PI-R Facet Scales, which are part of the IPIP project. IPIP is a project developed in 1996 by Lewis Goldberg. It was designed as one of international scientific collaboration, allowing access to personality assessment tools and facilitating the ongoing development of assessment scales with the international scientific community. The Romanian adaptation of the International Set of Personality Items: IPIP-Ro was made by Dragoș Iliescu, Marian Popa and Roxana Dimache, in a pilot study, in 2019 (Iliescu et al., 2019).

The NEO PI-R IPIP test is a questionnaire, included in IPIP project, based on the Big Five personality model, measuring the same features as the commercial NEO PI-R. This test allows the comprehensive testing of the human personality. It has five main scales, with 30 component subscales of the profile, providing sufficient information to evaluate the defining characteristics of the profile of each applicant.

Although the researches regarding the NEO PI-R IPIP variant in Romanian are at the beginning, the test results showed that he accurately measures what he intends to measure, having psychometric 
characteristics comparable to the commercial NEO PI$\mathrm{R}$ test.

The five main personality traits measured by this test are: Neuroticism, Extraversion, Openness to Experiences, Pleasantness and Conscientiousness. The Neuroticism Factor $(\mathrm{N})$ comprises 6 scales: Anxiety (N1), Anger-Hostility (N2), Depression (N3), Shyness (N4), Impulsivity (N5) and Vulnerability (N6).

For measuring the energy level we used the Jackson Personality Inventory [JPI-R], part of IPIP project, the Energy Level [Enl] Scale. The Jackson Personality Inventory-Revised provides an assessment of personality and evaluates a variety of social and cognitive factors, which affect an individual's functioning. It was developed by Douglas N. Jackson (Goldberg et. al., 2006) and the pilot study in Romania was done by Dragos Iliescu (Iliescu et al., 2019).

For measuring distrust, we used MPQ Alienation [AL] component of Tellegen's Multidimensional Personality Questionnaire [MPQ], which is also part of the IPIP project. The MPQ is a set of unidimensional self-report scales, each measuring a distinctive trait construct, which together would provide for a comprehensive assessment of normal personality. The current full-length version of the inventory (Tellegen, 2003) comprises 276 items. It contains 11 primary trait scales that operate as indicators of: Positive Emotionality (PEM), Negative Emotionality (NEM), and Constraint (CON). Alienation / distrust is as components of NEM.

We measured also parent's self-efficacy using the General Self-Efficacy Scale (GSE). (Schwarzer, 1995). The General Self-Efficacy Scale is a 10-item psychometric scale that was developed by Matthias Jerusalem and Ralf Schwarzer in 1981. It measures the optimistic self-beliefs to cope with a variety of difficult demands in life.

In the end, we used the Basic Psychological Need Satisfaction and Frustration Scale - General Measure (Chen et al., 2015) to measure the need satisfaction and the need frustration of the parents related to Covid-19 pandemic. The scale was translated by Cătălin Mosoia. This scale has 24 items assessing both need satisfaction and frustration in general in one's life including the three needs for competence, autonomy, and relatedness.

\section{Results}

The sample size of this study $(\mathrm{N}=128)$ is representative for the population studied, for an effect size of $|\rho|=0.3$ and $\alpha$ err prob. $=0.05$.

We examined the correlations between the following variables: anxiety, energy level, anger, distrust, self-efficacy, satisfaction or frustration with relatedness needs, satisfaction or frustration with competence needs and satisfaction or frustration with autonomy needs. We tested the following hypothesis:

H1: There is a significant relationship between the anxiety level and energy level in parents of children in primary school, during Covid-19 pandemic.

For testing the hypothesis we used the Pearson correlation, being fulfilled all the specific assumptions. The result $r=-0.15, p=.08$ did not show that there is a significant relationship between anxiety and the energy level in parents with children in the primary school, during the Covid 19 pandemic.

\section{H2: There is a significant relationship between the} anxiety level and the level of anger in parents of children in primary school, during Covid-19 pandemic.

For testing the hypothesis we used the Pearson correlation, being fulfilled all the specific assumptions. The results $r=0.48, p<.001$ showed that there is a significant relationship between anxiety and anger levels in parents of children in primary school, during Covid-19 pandemic. Moreover, the tested relationship shows a significant positive relationship between the 2 variables, therefore, as the level of anxiety increases, so does the level of anger in parents of children in primary school, during Covid-19 pandemic. Between the 2 variables, there is a $23 \%$ overlap.

H3: There is a significant relationship between the anxiety level and the level of satisfaction in relatedness needs in parents of children in primary school, during Covid-19 pandemic.

For testing the hypothesis we used the Pearson correlation, being fulfilled all the specific assumptions. The results $r=0.26, p=.002$ showed that there is a significant relationship between anxiety and the level of satisfaction in relatedness needs in parents of children in primary school, during Covid-19 pandemic. Moreover, the tested relationship shows a significant positive relationship between the 2 variables, therefore, as the level of anxiety increases, 
so does the level of satisfaction with relatedness needs of parents. Between the 2 variables there is an overlap of $6.76 \%$.

H4: There is a significant relationship between the anxiety level and the level of distrust in parents of children in primary school, during Covid-19 pandemic.

We used the Spearman correlation to test the hypothesis, because not all the specific assumptions for testing the Pearson correlation were met. The result showed that there is a significant relationship between anxiety and the level of distrust in parents: $\rho=0.22$, $p$ $=.012$. Moreover, the tested relationship shows a significant positive relationship between the 2 variables, therefore, as the level of anxiety increases, so does the level of distrust.

H5: There is a significant relationship between the level of anxiety and the level of self-efficacy in parents of children in primary school, during Covid-19 pandemic.

We used the Spearman correlation to test the hypothesis, because not all the specific assumptions for testing the Pearson correlation were met. The result showed that there is a significant relationship between anxiety and the level of self-efficacy in parents during the Covid-19 pandemic: $\rho=-0.29, p=.001$. Moreover, the tested relationship shows a significantly negative relationship between the 2 variables, therefore, as the level of anxiety increases, the level of self-efficacy decreases.

H6: There is a significant relationship between the level of anxiety and the level of satisfaction related to the needs of autonomy in parents of children in primary school, during Covid-19 pandemic.

We used the Spearman correlation to test the hypothesis, because not all the specific assumptions for testing the Pearson correlation were met. The result showed that there is a significant relationship between anxiety and the level of satisfaction related to autonomy needs in parents during the Covid-19 pandemic: $\rho=0.22, p=.011$. Moreover, the tested relationship shows a significant positive relationship between the 2 variables, therefore, as the level of anxiety increases, so does the level of satisfaction related to the needs of autonomy in parents during the Covid-19 pandemic.

H7: There is a significant relationship between the level of anxiety and the level of satisfaction related to the competence needs in parents of children in primary school, during Covid-19 pandemic.

We used the Spearman correlation to test the hypothesis, because not all the specific assumptions for testing the Pearson correlation were met. The result showed that there is a significant relationship between anxiety and the level of satisfaction of competence needs: $\rho=0.23, p=.009$. Moreover, the tested relationship shows a significant positive relationship between the 2 variables, therefore, as the level of anxiety increases, so does the level of satisfaction of competence needs.

H8: There is a significant relationship between the level of anxiety and the level of frustration in relatedness needs in parents of children in primary school, during Covid-19 pandemic.

We used the Spearman correlation to test the hypothesis, because not all the specific assumptions for testing the Pearson correlation were met. The result did not show that there is a significant relationship between anxiety and the level of frustration in relatedness needs of parents during the Covid-19 pandemic: $\rho=-0.14, \mathrm{p}=.112$.

H9: There is a significant relationship between the level of anxiety and the level of frustration related to the need for autonomy in parents with children in primary school, during the Covid pandemic 19.

We used the Spearman correlation to test the hypothesis, because not all the specific assumptions for testing the Pearson correlation were met. The result showed that there is a significant relationship between anxiety and the level of frustration related to the needs for autonomy during the Covid-19 pandemic: $\rho=$ $0.21, p=.016$. Moreover, the tested relationship shows a significantly negative relationship between the 2 variables, therefore, as the level of anxiety increases, the level of frustration related to the needs for autonomy decreases during the Covid-19 pandemic.

H10: There is a significant relationship between the level of anxiety and the level of frustration related to the competence needs in parents of children in primary school, during Covid-19 pandemic..

We used the Spearman correlation to test the hypothesis, because not all the specific assumptions for testing the Pearson correlation were met.The result showed that there is a significant relationship between anxiety and the level of frustration related to the competence needs in parents during the Covid-19 
pandemic: $\rho=-0.29, \mathrm{p}=.001$. Moreover, the tested relationship shows a significantly negative relationship between the 2 variables, therefore, as the level of anxiety increases, the level of frustration related to the competence needs decreases in parents during the Covid-19 pandemic.

The results are presented in Table 1 and Table 2, below:
Table 1. Results of correlation analysis between variables

\begin{tabular}{lcccc}
\hline \multicolumn{1}{c}{ Variables } & Anxiety & Energy & Anger & $\begin{array}{c}\text { Satisfaction } \\
\text { relatedness } \\
\text { needs }\end{array}$ \\
\hline Anxiety & 1 & -.15 & .48 & .26 \\
Energy & -.15 & 1 & -.30 & -.07 \\
Anger & .48 & -.30 & 1 & .37 \\
$\begin{array}{l}\text { Satisfaction } \\
\text { relatedness needs }\end{array}$ & .26 & -.07 & .37 & 1 \\
\end{tabular}

Table 2. Results of nonparametric correlation analysis between variables

\begin{tabular}{|c|c|c|c|c|c|c|c|c|}
\hline Variables & Anxiety & Distrust & $\begin{array}{c}\text { Self- } \\
\text { efficacy }\end{array}$ & $\begin{array}{c}\text { Satisfaction } \\
\text { autonomy } \\
\text { needs } \\
\end{array}$ & $\begin{array}{c}\text { Satisfaction } \\
\text { competence } \\
\text { needs }\end{array}$ & $\begin{array}{c}\text { Frustration } \\
\text { relatedness } \\
\text { needs }\end{array}$ & $\begin{array}{c}\text { Frustration } \\
\text { autonomy } \\
\text { needs }\end{array}$ & $\begin{array}{c}\text { Frustration } \\
\text { competence } \\
\text { needs } \\
\end{array}$ \\
\hline Anxiety & 1 & .22 & -.28 & .22 & .23 & -.14 & -.21 & -.29 \\
\hline Distrust & .22 & 1 & -.28 & .28 & .37 & -.35 & -.21 & -.24 \\
\hline Self-efficacy & -.28 & -.28 & 1 & -.19 & -.31 & .36 & .48 & .63 \\
\hline $\begin{array}{l}\text { Satisfaction } \\
\text { autonomy needs }\end{array}$ & .22 & .28 & -.19 & 1 & .62 & -.25 & -.22 & -.27 \\
\hline $\begin{array}{l}\text { Satisfaction } \\
\text { competence } \\
\text { needs }\end{array}$ & .23 & .37 & -.31 & .62 & 1 & -.34 & -.13 & -.20 \\
\hline $\begin{array}{l}\text { Frustration } \\
\text { relatedness } \\
\text { needs }\end{array}$ & -.14 & -.35 & .36 & -.25 & -.34 & 1 & .54 & .61 \\
\hline $\begin{array}{l}\text { Frustration } \\
\text { autonomy needs }\end{array}$ & -.21 & -.21 & .48 & -.22 & -.13 & .54 & 1 & .64 \\
\hline $\begin{array}{l}\text { Frustration } \\
\text { competence } \\
\text { needs }\end{array}$ & -.29 & -.24 & .63 & -.27 & -.20 & .61 & .64 & 1 \\
\hline
\end{tabular}

\section{Discussions}

Significantly negative correlations were found between anxiety and self-efficacy and between anxiety and frustration regarding competence needs. If the first correlation can be anticipated, the second was surprising. These results contradicted the results of several studies. For example, Nogas et al. (1974) found a negative correlation between death anxiety and the sense of competence. Thorough research would be needed to better understand this relation.

Significantly negative correlations were also observed between distrust and self-efficacy, distrust and frustration in relatedness needs, distrust and frustration related to competence needs and a significantly positive correlation between distrust and satisfaction with autonomy needs. A careful analysis of these relationships and the extent to which the pandemic situation has influenced these relationships is needed.

In terms of self-efficacy, significantly positive correlations were found between self-efficacy and frustration in relatedness needs, self-efficacy and frustration with autonomy needs, and self-efficacy and frustration with competence needs. These results were also surprising. One explanation could be the 
heterogeneity of the sample or the pandemic situation that could influence the results.

\section{Conclusions}

At this time, we all live unique life experiences, when a global pandemic has led to significant changes for almost every aspect of our daily lives.

The results of this study provide information about the experiences of parents in the first weeks of the COVID-19 pandemic, however, several limitations should be mentioned. Given the lack of a baseline, a pre-pandemic assessment of this sample, our results provide only a description of the early experiences of Romanian parents at the beginning of the COVID-19 pandemic (April-June). Stronger inferences require longitudinal data. Among the limitations of this study we mention, also, the size and the heterogeneity of the sample.

The psychological effects of the COVID-19 outbreak are still being studied. How this crisis, social distancing and restrictive measures affect the mental health of children and parents is a major challenge in the field (Holmes et al., 2020; C. Wang et al., 2020). Studying these effects and the results of these studies can help better inform researchers, social actors and policy makers to develop effective guidelines for future outbreaks, in order to promote the maintenance of mental health and encourage the well-being of families (Jiménez et al., 2019). This requires in particular prevention programs specifically geared to the needs of the family in the context of a health crisis. Specific tools have already been developed to increase family well-being during the pandemic (Coyne et al., 2020; Szabo et al., 2020) which could help improve family adjustment and parental behaviors (Romero et al., 2020).

\section{Acknowledgments}

This study was conducted with the financial support of the Human Capital Operational Program 2014-2020, through the POCU 123793 project entitled "Researcher, future entrepreneur - The new generation".

Authors note: The authors have equal contributions to this article.

Cristina S. Sălăgean is a $\mathrm{PhD}$. Student at "Education, Reflection, Development" Doctoral School, Babes-Bolyai University, in Cluj-Napoca. She is a private practice psychologist in the specialization of Special Psychopedagogy and has over 10 years of teaching and therapeutic intervention experience with children with Special Educational Needs. Her areas of interest for research are: Autism Spectrum Disorders, Applied Behavior Analysis and Inclusive Education.

Editha Coşarbă is a PhD. Student at "Education, Reflection, Development" Doctoral School, BabesBolyai University, in Cluj-Napoca. For 15 years she has worked as a speech therapist at the Arad County Center for Educational Resources and Assistance.

\section{References}

Bandura, A. (1983). Self-efficacy determinants of anticipated fears and calamities. Journal of Personality and Social Psychology, 45(2), 464-469.

Bradley, R. A. (2007). Parenting in the breach: How parents help children cope with developmentally challenging circumstances. Parenting, 7(2), 99-148.

Chen, B., Vansteenkiste, M., Beyers, W., Liesbet Boone, Deci, E. L., Van Der Kaap-Deeder, J., Duriez, B., Lens, W., Matos, L., Mouratidis, A., Ryan, R. M., Kennon, Sheldon, M., Soenens, B., Stijn, Petegem, V., \& Verstuyf, J. (2015). Basic psychological need satisfaction, need frustration, and need strength across four cultures. Springer, 39(2), 216-236.

Craig, L., \& Churchill, B. (2020). Dual-earner parent couples'work and care during COVID-19. Gender, Work \& Organization, 28 (S1), 66-67.

Cobham, V. E., McDermott, B., Haslam, D., \& Sanders, M. R. (2016). The Role of Parents, Parenting and the Family Environment in Children's Post-Disaster Mental Health. In Current Psychiatry Reports. Vol. 18, Issue 6, pp. 1-9. Current Medicine Group LLC 1.

Conger, R. D., Wallace, L. E., Sun, Y., Simons, R. L., McLoyd, V. C., \& Brody, G. H. (2002). Economic pressure in African American families: a replication and extension of the family stress model. Developmental Psychology, 38(2), 179-193.

Connor, K. M., \& Davidson, J. R. T. (2003). Development of a new Resilience scale: The Connor-Davidson Resilience scale (CD-RISC). Depression and Anxiety, 18(2), 76-82.

Costa, N. M., Weems, C. F., \& Pina, A. A. (2009). Hurricane Katrina and youth anxiety: The role of perceived attachment beliefs and parenting behaviors. Journal of Anxiety Disorders, 23(7), 935-941.

Coyne, L. W., Gould, E. R., Grimaldi, M., Wilson, K. G., Baffuto, G., \& Biglan, A. (2020). First things first: Parent psychological flexibility and self-compassion during COVID-19. Behavior Analysis in Practice, 1.

Deater-Deckard, K. (1998). Parenting stress and child adjustment: Some old hypotheses and new questions. Clinical Psychology: Science and Practice, 5(3), 314332.

Gassman-Pines, A., Ananat, E. O., \& Fitz-Henley, J. (2020). COVID-19 and parent-child psychological well- 
being.

Pediatrics,

$146(4)$

(https://doi.org/10.1542/peds.2020-007294).

Gewirtz, A., Forgatch, M., \& Wieling, E. (2008). Parenting Practices as Potential Mechanisms for Child adjustment Following Mass Trauma. Journal of Marital and Family Therapy, 34(2), 177-192.

Gordillo, R. G. (2020). COVID-19 and Labour Law: Spain. Italian Labour Law E-Journal Special Issue 1, 13(1S).

Holmes, E. A., O’Connor, R. C., Perry, V. H., Tracey, I., Wessely, S., Arseneault, L., Ballard, C., Christensen, H., Cohen Silver, R., Everall, I., Ford, T., John, A., Kabir, T., King, K., Madan, I., Michie, S., Przybylski, A. K., Shafran, R., Sweeney, A., ... Bullmore, E. (2020). Multidisciplinary research priorities for the COVID-19 pandemic: a call for action for mental health science. In The Lancet Psychiatry. Vol. 7, Issue 6, pp. 547-560. Elsevier Ltd.

Iliescu, D., Popa, M., \& Dimache, R. (2019). Adaptarea românească a Setului Internaţional de Itemi de Personalitate: IPIP-Ro. Psihologia Resurselor Umane, 13(1), 83-112.

Jiao, W. Y., Wang, L. N., Liu, J., Fang, S. F., Jiao, F. Y., Pettoello-Mantovani, M., \& Somekh, E. (2020). Behavioral and emotional disorders in children during the COVID-19 epidemic. The journal of Pediatrics, 221, 264.

Jiménez, L., Antolín-Suárez, L., Lorence, B., \& Hidalgo, V. (2019). Family education and support for families at psychosocial risk in Europe: Evidence from a survey of international experts. Health and Social Care in the Community, 27(2), 449-458.

Kaya, A., \& Fang, H.Y. (1997). Identification of Contaminated Soils by Dielectric Constant and Electrical Conductivity. Journal of Environmental Engineering, 123(2), 169-177.

Lindström, K., Lindblad, F., \& Hjern, A. (2011). Preterm birth and attention-deficit/hyperactivity disorder in schoolchildren. Pediatrics, 127(5), 858-865.

Masten, A. S., \& Osofsky, J. D. (2010). Disasters and their impact on child development: Introduction to the special section. Child Development, 81(4), 1029-1039.

Mazza, M., Marano, G., Lai, C., Janiri, L., \& Sani, G. (2020). Danger in danger: Interpersonal violence during COVID-19 quarantine. Psychiatry Research, 289, 113046.

McFarlane, A. C. (1987). Family functioning and overprotection following a natural disaster: The longitudinal effects of post-traumatic morbidity. Australian and New Zealand Journal of Psychiatry, 21(2), 210-218.

Mikkonen, J., \& Raphael, D. (2010). Social determinants of health: The Canadian facts. Available at: https://ses.sp.bvs.br/local/File/Social Determinants of Health_The Canadian Facts.pdf (Accessed at 20.10.2020).

Neece, C. L., Green, S. A., \& Baker, B. L. (2012). Parenting stress and child behavior problems: A transactional relationship across time. American Journal on Intellectual and Developmental Disabilities, 117(1), 4866.

Nogas, C., Schweitzer, K., \& Grumet, J. (1974). An investigation of death anxiety, sense of competence, and need for achievement. OMEGA-Journal of Death and Dying, 5(3), 245-255.

Norris, F. H., Friedman, M. J., Watson, P. J., Byrne, C. M., Diaz, E., \& Kaniasty, K. (2002). 60,000 Disaster victims speak: Part I. An empirical review of the empirical literature, 1981-2001. Psychiatry, 65(3), 207-239.

Parkes, D. C., Procaccia, A. D., \& Shah, N. (2015). Beyond dominant resource fairness: Extensions, limitations, and indivisibilities. ACM Transactions on Economics and Computation (TEAC), 3(1), 1-22.

Patrick, S. W., Henkhaus, L. E., Zickafoose, J. S., Lovell, K., Halvorson, A., Loch, S., Letterie, M., \& Davis, M. M. (2020). Well-being of Parents and Children During the COVID-19 Pandemic: A National Survey. Pediatrics, 146(4), e2020016824.

Prime, H., Wade, M., \& Browne, D. T. (2020). Risk and resilience in family well-being during the COVID-19 pandemic. American Psychologist, 75(5), 631-643.

Qiu, J., Shen, B., Zhao, M., Wang, Z., Xie, B., \& Xu, Y. (2020). A nationwide survey of psychological distress among Chinese people in the COVID-19 epidemic: Implications and policy recommendations. In General Psychiatry. Vol. 33, Issue 2, p. 100213. BMJ Publishing Group.

Rodrigo, M. J., Almeida, A., Spiel, C., \& Koops, W. (2012). Introduction: Evidence-based parent education programmes to promote positive parenting. In European Journal of Developmental Psychology. Vol. 9, Issue 1, pp. 2-10. Psychology Press.

Romero, E., López-Romero, L., Domínguez-Álvarez, B., Villar, P., \& Gómez-Fraguela, J. A. (2020). Testing the Effects of COVID-19 Confinement in Spanish Children: The Role of Parents' Distress, Emotional Problems and Specific Parenting. International Journal of Environmental Research and Public Health, 17(19), 6975.

Roskam, I., Brianda, M. E., \& Mikolajczak, M. (2018). A Step Forward in the Conceptualization and Measurement of Parental Burnout: The Parental Burnout Assessment (PBA). Frontiers in Psychology, 9(JUN), 758.

Russell, B. S., Hutchison, M., Tambling, R., Tomkunas, A. J., \& Horton, A. L. (2020). Initial Challenges of Caregiving During COVID-19: Caregiver Burden, Mental Health, and the Parent-Child Relationship. Child Psychiatry and Human Development, 51(5), 671682.

Sameroff, A. (2009). The transactional model. In The transactional model of development: How children and contexts shape each other. (pp. 3-21). American 
Psychological Association.

Sari, P., Pajarianto, H., Kadir, A., Galugu, N., \& Februanti, S. (2020). Study from Home in the Middle of the COVID19 Pandemic: Analysis of Religiosity, Teacher, and Parents Support Against Academic Stress. 12(2s), 17911807.

Schwarzer, R., \& Jerusalem, M. (1995). Generalized selfefficacy scale. In J. Weinman, S. Wright, \& M. Johnston (Eds.), Measures in health psychology: A user's portfolio. Causal and control beliefs. (pp. 35-37). Windsor, UK: NFER-NELSON.

Séjourné, N., Sanchez-Rodriguez, R., Leboullenger, A., \& Callahan, S. (2018). Maternal burn-out: an exploratory study. Journal of Reproductive and Infant Psychology, 36(3), 276-288.

Shea, S. E., \& Coyne, L. W. (2011). Maternal dysphoric mood, stress, and parenting practices in mothers of head start preschoolers: The role of experiential avoidance. Child and Family Behavior Therapy, 33(3), 231-247.

Sohrabi, C., Alsafi, Z., O’Neill, N., Khan, M., Kerwan, A., Al-Jabir, A., Iosifidis, C., \& Agha, R. (2020). World Health Organization declares global emergency: A review of the 2019 novel coronavirus (COVID-19). In International Journal of Surgery. Vol. 76, pp. 71-76. Elsevier Ltd.

Sorkkila, M., \& Aunola, K. (2020). Risk Factors for Parental Burnout among Finnish Parents: The Role of Socially Prescribed Perfectionism. Journal of Child and Family Studies, 29(3), 648-659.

Spinelli, M., Lionetti, F., Pastore, M., \& Fasolo, M. (2020). Parents' Stress and Children's Psychological Problems in Families Facing the COVID-19 Outbreak in Italy. Frontiers in Psychology, 11, 1713.

Szabo, T. G., Richling, S., Embry, D. D., Biglan, A., \& Wilson, K. G. (2020). From Helpless to Hero: Promoting Values-Based Behavior and Positive Family Interaction in the Midst of COVID-19. Behavior Analysis in Practice, 13(3), 568-576.

Tedeschi, R. G., Shakespeare-Finch, J., Taku, K., \& Calhoun, L. G. (2018). Posttraumatic growth: Theory, research, and applications. Routledge.

Tellegen, A. (2003). Multidimensional Personality Questionnaire (MPQ). Unpubl. manuscr., University.

Usher, K., Bhullar, N., Durkin, J., Gyamfi, N., \& Jackson, D. (2020). Family violence and COVID-19: Increased vulnerability and reduced options for support. International journal of mental health nursing, 29 (4), 549-552.

Wang, C., Pan, R., Wan, X., Tan, Y., Xu, L., Ho, C. S., \&
Ho, R. C. (2020). Immediate Psychological Responses and Associated Factors during the Initial Stage of the 2019 Coronavirus Disease (COVID-19) Epidemic among the General Population in China. International Journal of Environmental Research and Public Health, 17(5), 1729.

Wang, D., Hu, B., Hu, C., Zhu, F., Liu, X., Zhang, J., Wang, B., Xiang, H., Cheng, Z., Xiong, Y., Zhao, Y., Li, Y., Wang, X., \& Peng, Z. (2020). Clinical Characteristics of 138 Hospitalized Patients with 2019 Novel Coronavirus-Infected Pneumonia in Wuhan, China. JAMA - Journal of the American Medical Association, 323(11), 1061-1069.

Williford, A. P., Calkins, S. D., \& Keane, S. P. (2007). Predicting change in parenting stress across early childhood: Child and maternal factors. Journal of Abnormal Child Psychology, 35(2), 251-263.

Wu, M., Xu, W., Yao, Y., Zhang, L., Guo, L., Fan, J., \& Chen, J. (2020). Mental health status of students' parents during COVID-19 pandemic and its influence factors. General Psychiatry, 33(4).

Xie, X., Xue, Q., Zhou, Y., Zhu, K., Liu, Q., Zhang, J., \& Song, R. (2020). Mental health status among children in home confinement during the coronavirus disease 2019 outbreak in Hubei Province, China. In JAMA Pediatrics. Vol. 174, Issue 9, pp. 898-900. American Medical Association.

Zhou, P., Yang, X. Lou, Wang, X. G., Hu, B., Zhang, L., Zhang, W., Si, H. R., Zhu, Y., Li, B., Huang, C. L., Chen, H. D., Chen, J., Luo, Y., Guo, H., Jiang, R. Di, Liu, M. Q., Chen, Y., Shen, X. R., Wang, X., ... Shi, Z. L. (2020). A pneumonia outbreak associated with a new coronavirus of probable bat origin. Nature, 579(7798), 270-273.

Digi24, Astăzi este ultima zi de stare de urgenţă în România. Ce se schimbă când intră în vigoare starea de alertă, Available at: https://www.digi24.ro/stiri/actualitate/astazi-esteultima-zi-de-stare-de-urgenta-in-romania-starea-dealerta-intra-insa-in-vigoare-peste-trei-zile-1306802 (accessed at 07.11.2020).

World Health Organization, WHO Director-General's remarks at the media briefing on 2019-nCoV on 11 February 2020, Available at: https://www.who.int/directorgeneral/speeches/detail/who-director-general-sremarks-at-the-media-briefing-on-2019-ncov-on-11february-2020 (accessed at 07.11.2020). 